\title{
Association of family history of schizophrenia and history of obstetric complications at birth: relationship with age at onset and psychopathology dimensions in a Nigerian cohort
}

\author{
Justus Uchenna Onu ${ }^{1}$, Jude Uzoma Ohaeri ${ }^{2}$
}

1. Department of Mental Health, Faculty of Medicine, Nnamdi Azikiwe University, Awka, Anambra State, Nigeria.

2. Department of Psychological Medicine, University of Nigeria, Nsukka, Enugu Campus, Enugu State, Nigeria.

\begin{abstract}
Background: The nature of the association between obstetric complications (OCs) at birth and the genetic aetiology of schizophrenia remains unclear, as some authors suggest that it is an independent risk factor while others support either interactionism or an epiphenomenon perspective.

Objective: To examine the association of family history of schizophrenia (FHS) with history of OCs, with a view to assessing whether this relationship moderates clinical phenotypes such as symptom dimensions and age at onset of illness.

Methods: This study examined OCs among schizophrenia probands using the Obstetric Complications Scale. An inquiry into family history was performed using the Family history method. Psychopathological symptom dimensions were assessed using standard scales. Data were analyzed to examine the interaction of FHS and history of OCs with age at onset and symptom dimensions, using ANCOVA.
\end{abstract}

Results: FHS was significantly associated with the disorganized symptoms dimension $(\mathrm{p}=0.03)$. History of OCs was significantly associated with earlier age at onset ( $\mathrm{p}=0.007)$. However, in ANCOVA, the effect of the interaction between FHS and history of OCs was not significant for age at onset and symptom dimensions $(\mathrm{P}=0.059)$.

Conclusion: FHS was significantly associated with disorganization syndrome, and OCs was significantly associated with age at onset.

Keywords: Family history; schizophrenia; obstetric complications; symptom dimensions; age at onset.

DOI: https://doi.org/10.4314/ahs.v20i2.21

Cite as: Onu JU, Ohaeri JU. Association of family history of schizophrenia and history of obstetric complications at birth: relationship with age at onset and psychopathology dimensions in a Nigerian cohort. Afri Health Sci. 2020; 20(2): 697-708. https:/ / doi.org/ 10.4314/ahs.v20i2.21

\section{Corresponding author: \\ Justus Uchenna Onu, Department of Mental Health, Faculty of Medicine, Nnamdi Azikiwe University, Awka, Anambra State, Nigeria. Phone number: +2348034198509 \\ E-mail address: just20002006@gmail.com; \\ Jude Uzoma Ohaeri, Department of Psychological Medicine, University of Nigeria, Nsukka, Enugu Campus, Enugu State, Nigeria.}

\section{Introduction}

Schizophrenia is a heterogeneous group of disorders affecting about $1 \%$ of the general population ${ }^{1}$. Genetics, environmental risk factors and their interactions are linked to higher likelihood of developing schizophrenia in accordance with the neurodevelopmental hypothesis of the disease $^{2}$. An environmental factor that has been studied in this regard is obstetric complication at birth, with a focus on whether it interacts with family history to impact on age at onset of disease as well as type and severity of psychopathology $y^{3,4}$. An excess of history of obstetric complications at birth (OCs) in patients with schizophrenia has been reported ${ }^{5}$. However, less consistent results have also been reported concerning the relationship between 
OCs and family history of schizophrenia ${ }^{6,7}$. The controversy is centered on the association of OCs with genetic loading, with some studies finding an association ${ }^{8,9}$ and others not finding one $\mathrm{e}^{6,10}$. Thus, the association between genetic factors and obstetric complications remains controversial. Hence, there is an uncertainty about the role of obstetric complications as an independent risk factor for schizophrenia. This is centered on whether there is a potential for OCs to interact with genetic risk to increase liability for the disease, and moderate the expression of clinical phenomena, such as the age at onset of illness and symptom dimensions or clinical phenotypes (i.e., so called positive, negative and disorganization symptoms). Another speculation is whether the diease is an epiphenomenon of developmental process in individuals already on the path towards psychotic illness in adult life. An examination of the rate of obstetric complications in patients with or without family history of illness can help clarify the relationship between obstetric complications and schizophrenia.

Another important consideration in the genetics of schizophrenia is the association of family history of schizophrenia with the clinical phenotypes (positive, negative and disorganized dimensions) and age at onset. $\mathrm{Pa}$ tients with schizophrenia are frequently reported to show positive, negative, and disorganized symptomatology ${ }^{11}$. It is unclear if the expression of these symptoms is moderated by environmental factors, such as OCs; or whether they represent any of the following possibilities: (i) three underlying distinct disorders; (ii) a differing severity of the same disorder; (iii) symptoms at different stages of the illness; (iv) individual differences in the reaction to the same disorder; or (v) a combination of these factors. The search for which symptom dimensions are more heritable is useful in psychiatric genetics to validate phenotypes that have more relationship with the genetic aetiology of schizophrenia ${ }^{12}$. There is no consensus from family studies of which symptom dimension is more heritable. However, most studies have indicated either the disorganized dimension or the negative symptoms dimension ${ }^{13,14}$. Concerning the relationship between OCs, symptom dimensions and age at onset, most studies agree that obstetric complications potentially damage the brain during pregnancy and delivery and are common in schizophrenia with early onset ${ }^{15}$. There is also literature linking brain abnormality with symptom dimensions (negative symptoms) and poor prognosis ${ }^{16}$.
Although it is well known that there are cross-cultural variations in certain aspects of the schizophrenia syndrome, the association between family history of schizophrenia, OCs, symptom dimensions and age at onset of illness has received little attention in the literature from African populations. Inquiry into this association is necessary because of the impression that obstetric complications are still highly prevalent in the developing countries of Africa ${ }^{17}$. Hence, this study was done to examine the following research questions:

1. Is there a significant association between family history of schizophrenia, on the one hand, and OCs at birth, symptom dimensions and age at onset of illness, on the other hand, among a Nigerian schizophrenia cohort? 2. Is there a significant association between history of OCs at birth, on the one hand, and symptom dimensions and age at onset of illness, on the other hand, among a Nigerian schizophrenia cohort?

3. When family history of schizophrenia is present in addition to history of OCs at birth, do these interact to moderate the expression of clinical phenotypes such as symptom dimensions and age at onset of illness?

\section{Materials and methods}

The study lasted 6-months starting from $1^{\text {st }}$ October, 2015 to $31^{\text {st }}$ March, 2016.

\section{Ethical consideration}

Approval for this study was obtained from the Ethics and Research Committee of the Federal Neuropsychiatric Hospital, Enugu, with reference number FNHE/ HCS\&T/REA/VOL.1/176. This was approved on $23^{\text {rd }}$ of March, 2015 as part of a larger study on genetic epidemiology of schizophrenia. International ethical norms and standards were strictly adhered to. Written informed consent was obtained from all the participants. Participation was voluntary.

\section{Study design and population}

This was a cross-sectional study. The study was carried out among patients of the Federal Neuropsychiatric Hospital $(\mathrm{FNH})$, Enugu, which is one of the eight specialist Psychiatric Hospitals established by the Federal Government of Nigeria. It is located within Enugu metropolis and provides mental health care for people within the South Eastern part of Nigeria and neighbouring geopolitical zones. Consecutive in-patients admitted into the wards, who gave permission for their mothers and other 
relatives to be approached, were recruited into the study. Patients aged 18-64 years whose diagnoses were made at least one year prior to sampling (to allow for stability of diagnosis) were included in the study. Patients with schizophrenia of suspected organic aetiology (including substance use disorders), medical and psychiatric co-morbidities, were excluded through a detailed medical history, mental state examination, and full physical examination (including neurological examination). Also excluded were those whose mothers were not available or could not give details of their obstetric histories. Only in-patients were involved because of the lengthy time of interview and also because the admission period was an opportune time to locate many family members, especially during visiting hours. Patients were interviewed when they were in stable clinical conditions (fully conscious, could follow the interview process, and not requiring emergency chemical and/or physical restraint).

\section{Sample selection}

Study subjects from the various wards were recruited as listed in the hospital's admission register, which is a record of patients by date of admission and diagnosis. A total of 250 patients were admitted into the various wards in the 6-month period of the study. This study is part of a larger study on genetic epidemiology of schizophrenia which sought to evaluate the morbid risk, obstetric complications and handedness among patients with schizophrenia ${ }^{18,19}$. Based on the finding that the morbid risk of schizophrenia in first-degree relatives was 5.0\%, compared with $0.8 \%$ for the control group, we computed the required sample size using Cochran formula for comparison groups $(2 \mathrm{z} 2 \mathrm{pq} / \mathrm{d} 2)$ and arrived at 124, each, for patients and comparison group. Of the 250 patients admitted, 161 had a clinical diagnosis of schizophrenia by the unit consultant. The 161 patients were approached and after complete description of the study, six declined to give consent due to unwillingness to participate. The remaining 155 were recruited for the study after obtaining a written informed consent. After re-assessment, 17 were excluded either because of suspected organic aetiology, mother not available for interview, or illness had not lasted up to 1 year. The diagnosis of the remaining 138 subjects was confirmed using the Mini International Neuropsychiatric Interview (MINI).

\section{Procedure and measurement Diagnostic interview}

Diagnosis of schizophrenia was made using the ICD-10 criteria for schizophrenia and confirmed using the Mini International Neuropsychiatric Interview (MINI). One senior resident doctor in psychiatry applied the MINI, while two other senior resident doctors in psychiatry applied the family history diagnostic interviews. They were trained to apply the study instruments by a senior psychiatrist with experience in the use of these instruments. At the preliminary stage of the study, they took turns in interviewing patients not involved in the study. The study commenced when it was judged that the resident doctors could confidently use the questionnaires to interview the participants in the prescribed manner.

\section{Family history interview}

The family interview for patients and their relatives was done by two trained senior psychiatry residents, using the Family Interview for Genetic Studies (FIGS ${ }^{20}$. Details about the ascertainment of family history of mental illness have been presented elsewhere ${ }^{18}$.

\section{Obstetric history and other clinical interviews Lewis and Murray Obstetric Complication Scale}

Information on obstetric complications was obtained by maternal interview using the Lewis and Murray Obstetric Complication Scale. Subjects were rated as having definite or no complications. The Lewis obstetric complication scale is an "atheoretical scale" designed to measure indices of obstetric health, broadly defined as conditions during the mother's pregnancy combined with factors related to the delivery and neonatal health status ${ }^{21}$. Intended sources of information when using the scale may be the mother or birth records. In this study, the mother provided the birth history.

\section{Brief Psychiatry Rating Scale (BPRS)}

The BPRS is a widely used instrument for assessing the severity of positive, negative, general and affective symptoms of individuals who have severe mental disorders; especially schizophrenia ${ }^{22}$. The BPRS consists of 18-symptom constructs and takes 20-30 minutes for the interview and scoring. It is rated on a Likert scale of 1 (not present) to 7 (extremely severe) or 0-6 in the new version. In this study, the 0-6 scoring was used. It has good internal 
consistency (Cronbach's alpha) of 0.81-0.91, and generally high validity when compared with other measures of general psychopathology ${ }^{23}$.

\section{Scale for the Assessment of Negative symptoms (SANS)}

The Scale for the Assessment of Negative Symptoms (SANS) was developed by Nancy Andreasen and was first published in $1984^{24}$. SANS is a rating scale to measure negative symptoms in schizophrenia. It consists of 5 domains, and within each domain separate symptoms are rated from 0 (absent) to 5(severe). It has acceptable internal consistency (Cronbach's alpha) of $0.89^{25}$.

\section{History of the age at onset of illness}

Age at onset of illness was defined as the age of the patient at the first noticeable change in behaviour. It was obtained from both the patient and the significant other, separately. In cases of disparity, further information was sought and the illness onset was dated in a consensus.

\section{Data analysis}

The results were analysed using the Statistical Packages for Social Sciences, version 18. We assessed the association of family history of schizophrenia with obstetric complications using chi-square. The interaction of family history and history of OCs with age at onset and symptom dimensions was analyzed using Analysis of Covariance (ANCOVA).

\section{Results}

Table 1 shows the socio-demographic and some clinical characteristics of the 138 schizophrenia participants. The mean age of the participants was $31.76 \pm 10.40$ years. The mean duration of the illness was $8.01 \pm 8.87$ years. Mean age at onset was similar for males (23.6yrs) and females (24.4yrs). The majority $(52.9 \%)$ were males, never married $(76.8 \%)$, had formal education above primary school level $(84.8 \%)$ and were unemployed $(72.4 \%)$.

Table 1: Sample characteristics

\begin{tabular}{|c|c|c|}
\hline Characteristics & $(\mathrm{N}=138)$ & Stat. difference \\
\hline Mean Age & $31.76 \pm 10.40$ & \\
\hline Age at Onset (years) & $23.97 \pm 7.12$ & \\
\hline $\begin{array}{l}\text { Age at onset (Male) } \\
\text { Age at onset } \\
\text { (Female) }\end{array}$ & $\begin{array}{l}23.63 \pm 7.57 \\
24.35 \pm 6.61\end{array}$ & $\begin{array}{c}\mathrm{t}=-0.59, \mathrm{df}=136 \\
\mathrm{p}=0.55\end{array}$ \\
\hline Duration of illness (years) & $8.61 \pm 8.87$ & \\
\hline \multicolumn{3}{|l|}{ Gender } \\
\hline Male & $73(52.9 \%)$ & \\
\hline Female & $65(47.1 \%)$ & \\
\hline \multicolumn{3}{|l|}{ Marital Status } \\
\hline Never Married & $106(76.8 \%)$ & \\
\hline Married & $21(15.2 \%)$ & \\
\hline Separated/Divorced/Widowed & $11(8.0 \%)$ & \\
\hline \multicolumn{3}{|l|}{ Educational Status } \\
\hline No formal education & $3(2.2 \%)$ & \\
\hline Primary education & $18(13 \%)$ & \\
\hline Secondary education & $80(58.0 \%)$ & \\
\hline Tertiary education & $37(26.8 \%)$ & \\
\hline \multicolumn{3}{|l|}{ Employment Status } \\
\hline Unemployed & $100(72.4 \%)$ & \\
\hline Working part-time & $10(7.2 \%)$ & \\
\hline Working full time & $28(20.4 \%)$ & \\
\hline
\end{tabular}


The association of family history of schizophrenia with obstetric complications at birth is shown in table 2. Although there was no significant association between family history of schizophrenia and history of OCs at birth even with Yate's correction $\left(\chi^{2}=0.26, \mathrm{df}=1, \mathrm{p}=0.37\right)$, subjects from multiply affected families had higher prevalence of OCs at birth. For example, of those with no family history, $16.7 \%$ had history of OCs; for those with single family member affected, $19.2 \%$ had history of OCs; while of those with history of multiply affected family members, $33.3 \%$ had history of OCs.

Table 2: Family history of schizophrenia versus history of obstetric complications at birth of schizophrenia proband

$(\mathrm{N}=138)$

\begin{tabular}{|c|c|c|c|c|}
\hline \multirow{2}{*}{\multicolumn{2}{|c|}{ FHS }} & \multicolumn{2}{|c|}{ History of Definite OCs } & \multirow[t]{2}{*}{ Statistical Difference } \\
\hline & & Yes & No & \\
\hline No $\operatorname{FHS}(n=48)$ & & $8(16.7 \%)$ & $40(83.3 \%)$ & \\
\hline Only & one & $10(19.2 \%)$ & $42(80.8 \%)$ & $\chi^{2}=1.26 ; \mathrm{df}=1 ; p=0.26^{*}$ \\
\hline $\operatorname{FHS}(n=52)$ & & & & \\
\hline $\begin{array}{l}\text { Multiple } \\
(\mathrm{n}=36)\end{array}$ & FHS & $12(33.3 \%)$ & $24(66.7 \%)$ & \\
\hline
\end{tabular}

The psychopathological scores for those with family history of schizophrenia versus those without family history, were not significantly different for positive symptoms (7.6 \pm 5.1 versus $6.3 \pm 5.1)$ and negative symptoms

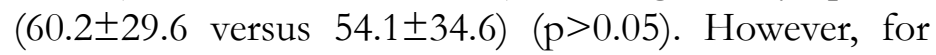
the disorganization syndrome, those with family history had significantly higher scores $(6.5 \pm 3.2$ versus $4.5 \pm 3.0$, $\mathrm{t}=2.2, \mathrm{df}=136, \mathrm{p}=0.03)$. For the association of history of OCs and symptom dimensions, there were higher psychopathological scores in the presence of OCs. This did not reach significance for positive syndrome $(8.7 \pm 5.1$ versus $7.5 \pm 5.0)$ and negative syndrome $(64.0 \pm 28.3$ versus $55.2 \pm 32.3)$, as well as the disorganization syndrome $(6.1 \pm 3.2$ versus $5.1 \pm 3.2, \mathrm{t}=1.8, \mathrm{df}=136, \mathrm{p}=0.08)$ as shown in table 3 . 
Table 3: Family history of schizophrenia and history of obstetric complications versus symptom dimensions of schizophrenia patients

\begin{tabular}{|c|c|c|c|c|c|c|}
\hline Variables & PSD & $\begin{array}{l}\text { Stat. } \\
\text { difference }\end{array}$ & NSD & $\begin{array}{l}\begin{array}{l}\text { Stat. } \\
\text { difference }\end{array} \\
\end{array}$ & DSD & $\begin{array}{l}\begin{array}{l}\text { Stat. } \\
\text { difference }\end{array} \\
\end{array}$ \\
\hline \multicolumn{7}{|l|}{ FHS } \\
\hline Yes & $7.63 \pm 5.13$ & $\mathrm{t}=1.37$ & $60.17 \pm 29.60$ & $\mathrm{t}=1.04$ & $6.45 \pm 3.22$ & $\mathrm{t}=2.16$ \\
\hline & & $\mathrm{df}=136$ & & $\mathrm{df}=136$ & & $\mathrm{df}=136$ \\
\hline No & $6.33 \pm 5.06$ & $\mathrm{p}=0.17$ & $54.14 \pm 34.59$ & $\mathrm{p}=0.30$ & $4.52 \pm 3.01$ & $\mathrm{p}=0.03$ \\
\hline History of OCs & $8.72 \pm 5.12$ & $\mathrm{t}=2.45$ & $64.57 \pm 28.29$ & $\mathrm{t}=1.67$ & $6.09 \pm 3.15$ & $\mathrm{t}=1.77$ \\
\hline Yes & & $\mathrm{df}=136$ & & $\mathrm{df}=136$ & & $\mathrm{df}=136$ \\
\hline No & $7.49 \pm 4.99$ & $\mathrm{p}=0.12$ & $55.22 \pm 32.25$ & $\mathrm{p}=0.10$ & $5.07 \pm 3.22$ & $\mathrm{p}=0.08$ \\
\hline
\end{tabular}

As reported in table 4, on the history of OCs and age at onset of illness, it was observed that patients with history of OCs became ill averagely about 4 years earlier than those without a history of OCs $(t=-2.72, d f=136$, $\mathrm{p}=0.007)$.
In view of these trends for higher psychopathological scores and lower age at onset in the presence of family history of schizophrenia and history of OCs, the data were subjected to Analysis of Covariance (ANCOVA), in order to see whether there was a significant interaction between family history of schizophrenia and history of OCs on the values of psychopathological scores and age at onset. 
Table 4: Family history of schizophrenia and history of obstetric complications versus age at onset of schizophrenia

$(\mathrm{N}=138)$

\begin{tabular}{lll}
\hline Family history of Schizophrenia & Age at Onset & Statistical Difference \\
\hline Variables & & \\
Yes & $23.98 \pm 7.11$ & $\mathrm{t}=0.02, \mathrm{df}=136, \mathrm{p}=0.98$ \\
No & $23.95 \pm 7.22$ & \\
History of OCs & & \\
Yes & $21.70 \pm 6.06$ & $\mathrm{t}=-2.72, \mathrm{df}=136, \mathrm{p}=0.007$ \\
& & \\
No & $25.12 \pm 7.36$ &
\end{tabular}

OCs= Obstetric Complications at birth

In figure 1, the interaction between family history of schizophrenia and history of OCs, for disorganized syndrome (as dependent variable), with duration of illness as a covariate, failed to reach significance $(\mathrm{p}=0.059)$. Family history made a significant contribution in this interaction $(\mathrm{F}=4.4, \mathrm{p}=0.04)$, but the corrected model for the total interaction failed to reach significance $(\mathrm{p}=0.059)$.

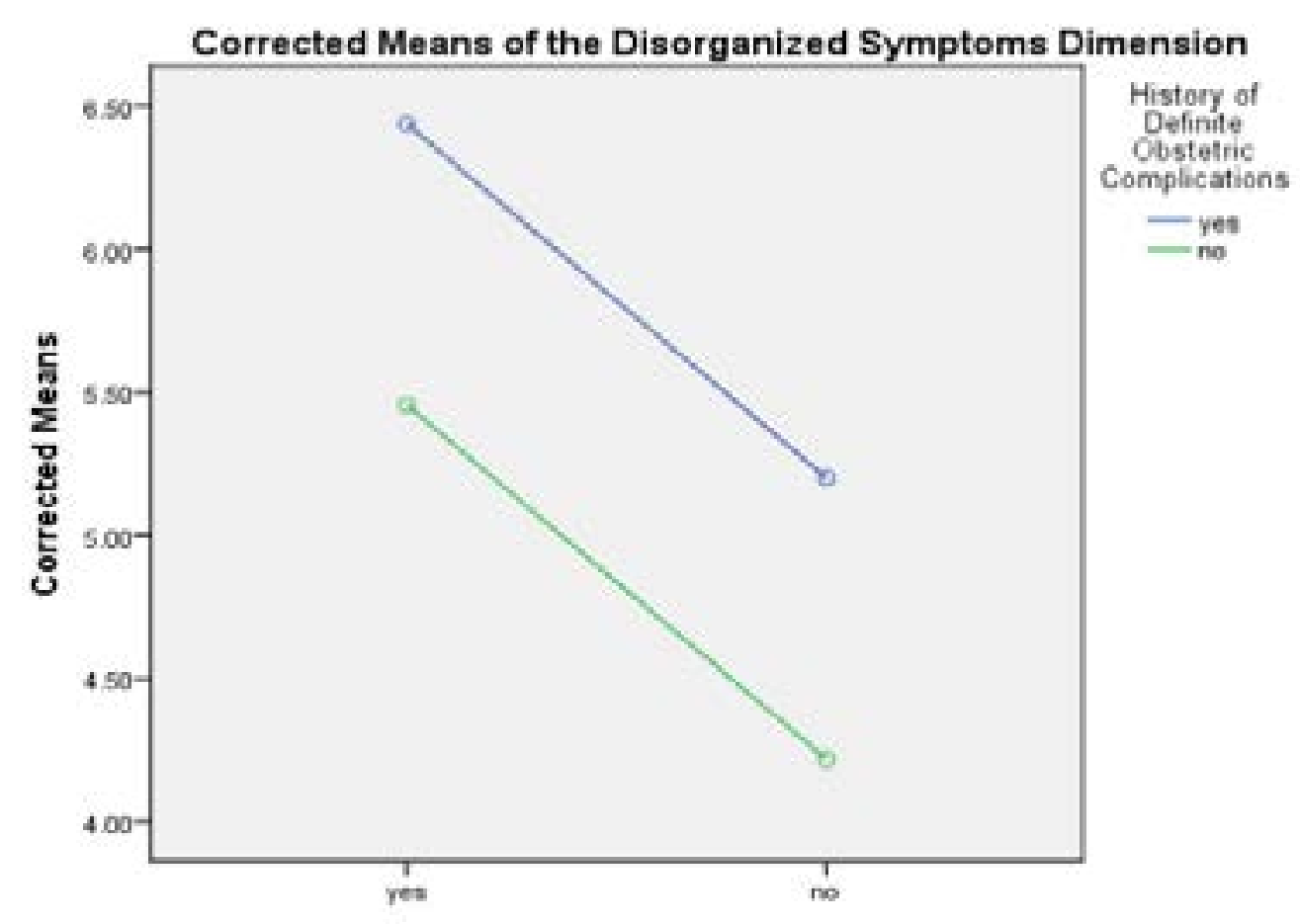

Family History of Sehizophrenia

Covariates appearing in the model are evaluated at the following values: duration of illness of patient years $=8.6087$

Figure 1: Line graph showing the interaction between family history of schizophrenia and history of obstetric complications on disorganized symptoms dimension. 
Similarly in figure 2, the interaction between family history of schizophrenia and history of OCs, for positive syndrome (as dependent variable), with duration of illness as a covariate, failed to reach significance $(\mathrm{F}=2.5$, $\mathrm{p}=0.059)$ and the significant contributor to the interaction was family history of schizophrenia $(\mathrm{F}=4.4, \mathrm{p}=0.04)$.
In analyzing the interaction between history of OCs and family history of schizophrenia with respect to age at onset of illness (as dependent variable, gender as covariate), we found that the interaction just failed to reach significance $(\mathrm{F}=2.6, \mathrm{p}=0.057)$, and the significant contributor to this interaction was $\mathrm{OCs}(\mathrm{F}=7.3, \mathrm{P}=0.008)$ as shown in figure 3.

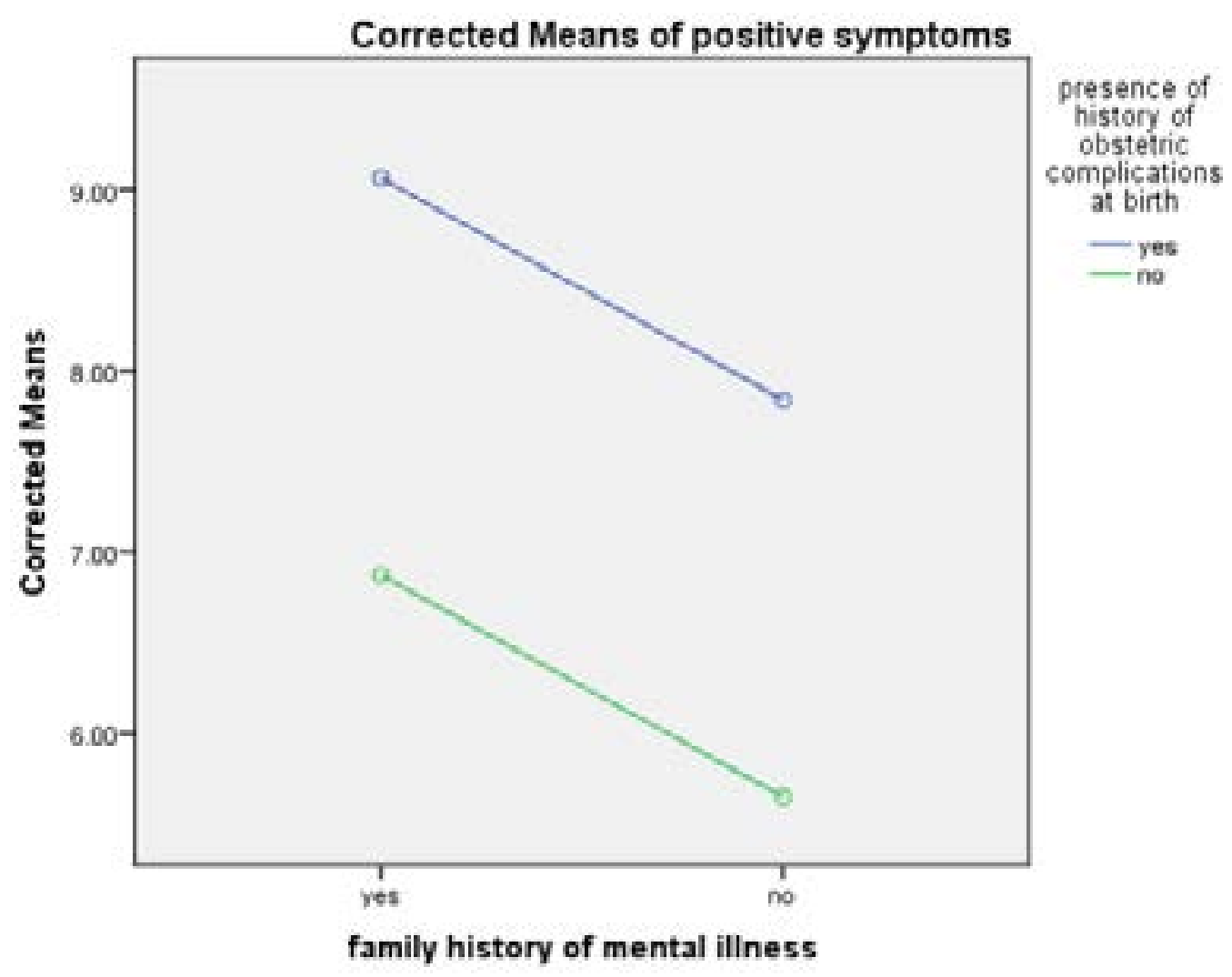

Covariates appearing in the model are evaluated at the following values: duration of illness of patient years $=8.6087$

Figure 2: Line graph showing the interaction between family history of schizophrenia and history of obstetric complications on positive symptoms dimension. 


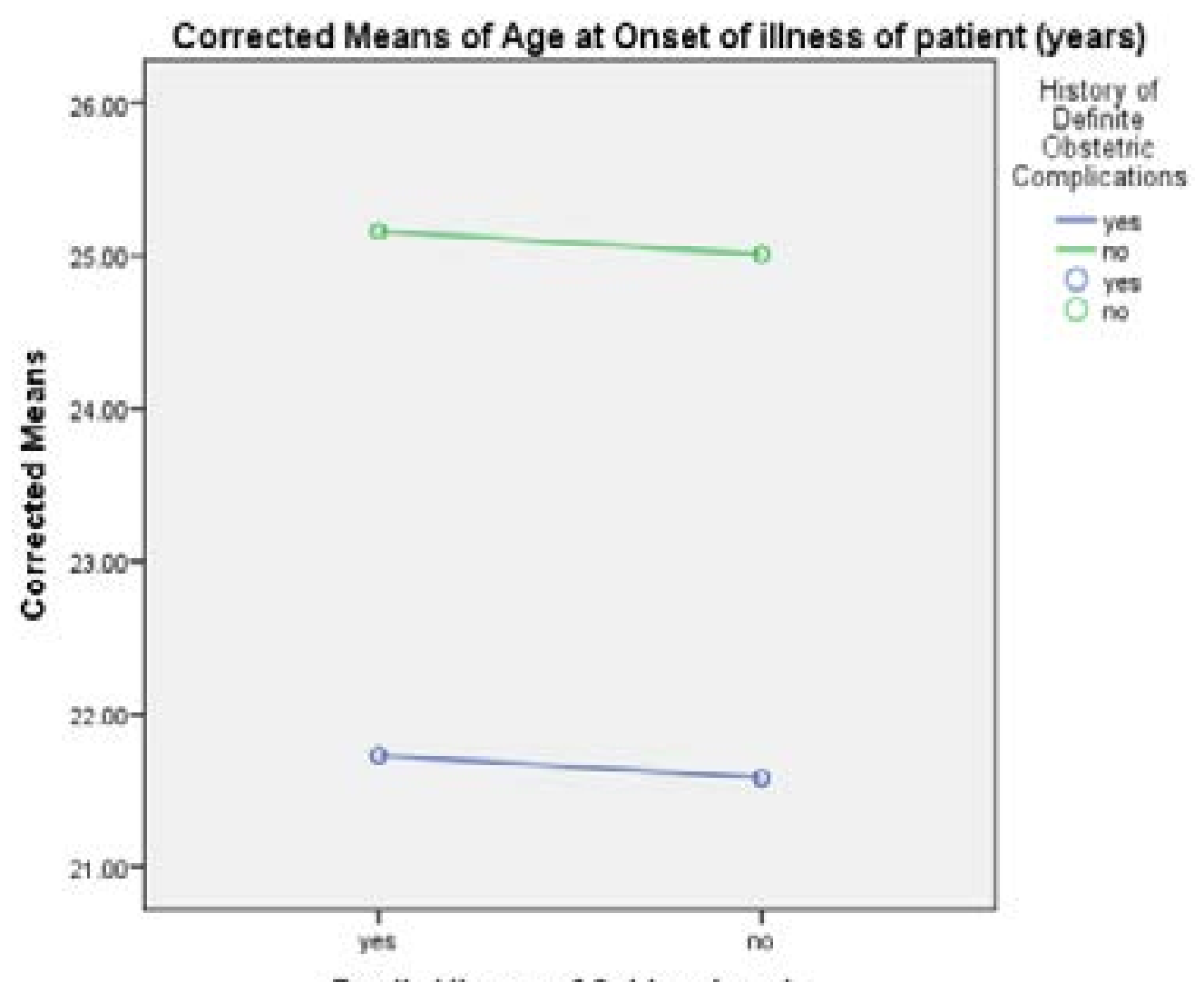

Family History of Schizophrenia

Corariates appearing in the model are evaluated at the following values: gender of patient $=1.4710$

Figure 3: Line graph showing the interaction between family history of schizophrenia and history of obstetric complications on age at onset of illness.

In other words, the effect of the interaction between FHS and history of OCs was non-significant $(\mathrm{p}=0.059)$, when these two factors were simultaneously positive, for higher scores on the disorganization and positive syndromes, and a lower age at onset of illness

\section{Discussion}

The study sought to explore the relationship of family history of schizophrenia (FHS) with history of obstetric complications at birth (OCs) among probands, in order to see whether the simultaneous presence of these two factors would have an additive effect on the type of psychopathology and age at onset of illness.

We found that, in the univariate analyses, there was a tendency for higher psychopathological scores in the presence of family history of schizophrenia which reached significance for disorganization syndrome. On the other hand, age at onset was significantly lower (on average by 4 years) for those with history of OCs $(\mathrm{p}=0.007)$.
In the multivariate analyses, the effect of the interaction between FHS and history of OCs was non-significant $(p=0.059)$, when these two factors were simultaneously positive, for higher scores on the disorganization and positive syndromes, and a lower age at onset of illness.

\section{Family history of schizophrenia and obstetric com- plications}

Despite the tendency for a dose-response situation, whereby probands from multiply affected families had higher prevalence of OCs $(33.3 \%)$ compared with those with no family history $(16.7 \%)$, and those with only one other family member affected $(19.2 \%)$, this trend did not reach significance. We found no evidence to support the notion in the literature that obstetric complications are themselves a manifestation of genetic risk to schizophrenia. Our finding is in line with those of some studies ${ }^{6,10}$. To prove such an association would require a more rigorous methodology, such as representative, larger sample 
size and follow-up studies. Although obstetric complications remain the most documented environmental indicators of risk for schizophrenia, the pathogenic role they play in the aetiology of schizophrenia is uncertain.

\section{Family history and schizophrenia symptom dimen- sions}

It is well established by factor analysis that there are at least three symptom dimensions (positive, negative, and disorganized) in schizophrenia ${ }^{16}$. However, it is not clearly known if genetic factors contribute to the variations in these syndromes. Our finding is in support of a possible genetic contribution to the disorganization dimension. This is consistent with the results of other studies ${ }^{26,27}$, thus underscoring the impression that the disorganized syndrome is a core clinical phenotype of schizophrenia. Our finding with regards to disorganized, positive and negative symptoms dimension and family history is in line with the result from molecular genetic studies of the relationship between genes and psychopathological dimensions of schizophrenia ${ }^{27-29}$. DeRosse et al. ${ }^{27}$ reported that disorganization syndrome was associated with multiple single nucleotide polymorphisms (SNPs) in chromosome 6q, the positive symptoms dimension was associated with one SNPs in chromosome 6q, while the negative symptoms dimension was not significantly associated with any of the SNPs studied (6q, 6p, and 20pq).

\section{Obstetric Complications versus age at onset of schizophrenia}

We found a significant association between history of OCs and age at onset, such that, on average, schizophrenia probands with history of OCs became ill 4 years earlier than those without history of OCs. Our finding is in line with majority of studies in this area ${ }^{3,30,31}$. However, the pathophysiological link between history of OCs and age at onset of schizophrenia remains to be clarified. Some scholars have hypothesized that foetal hypoxia may be a risk factor for early age at onset ${ }^{15}$.

\section{Interaction of OCs and family history on schizo- phrenia phenotypes}

The gene-environment interaction model of schizophrenia posits that the occurrence of an obstetric complication in a genetically vulnerable individual would increase the likelihood of that individual developing schizophre- nia. Alternatively, that the genetic and obstetric risk factors for schizophrenia occur independently of each other but additively influence risk of schizophrenia expres$\operatorname{sion}^{32}$. Our findings in Figures 1-3 did not support either of these models for the psychopathological dimensions and lower age at onset of illness. However, the significant association between history of OCs and age at onset of illness such that patients with history of obstetric complication developed schizophrenia earlier is important for driving primary prevention in developing countries, where obstetric complications are still high. Regarding the interaction between these variables on the phenotypes of schizophrenia, more studies are still needed to clarify these interactions, if there is any.

\section{Limitations}

Maternal recall bias is a limitation. Secondly, we did not determine the relationship of specific OCs and its severity on our outcome variables.

\section{Conclusion}

Family history of schizophrenia was significantly associated with disorganization symptoms dimension while OCs was significantly associated with earlier age at onset. There was no significant interaction between FHS and OCs on the dimensions of psychopathology and age at onset of illness in this study.

\section{Acknowledgments}

The authors would like to thank Dr. J.U. Onwukwe, the Medical Director, Federal Neuropsychiatric Hospital, Enugu, for providing the enabling environment and some logistic support for this study. Additionally, we thank Mr. Lewis Okanchi of the Federal School of Statistics for his insightful comments on the statistical methods, Drs. M.C. Inechi and B.N. Nweze for assistance in interviewing the relatives, and Drs. N.N. Unaogu and V.N. Ubochi for supervisory roles. We are grateful to the patients and their relatives for freely giving their time to participate in the study.

\section{Disclosure statement}

There is no conflict of interest.

\section{Funding sources}

Self-financed. 


\section{Author contributons}

Justus Uchenna Onu was the primary investigator. However, the first and second authors contributed to the study design, analysis and interpretation of data and drafting of the manuscript. The final draft of the manuscript was read and approved by both authors.

\section{References}

1. World Health Organization. The Global burden of diseases 2004 update, Geneva Switzerland: World Health Organization press, 2008.

2. McNeil TF. Perinatal risk factors and schizophrenia: selective review and methodological concerns. Epidemiol Rev 1995; 17:107-12.

3. O' Callaghan E, Gibson T, Colohan HA, Buckley P, Walshe DG, Larkin C et al. Risk of schizophrenia in adults born after obstetric complications and their association with early onset of illness: a controlled study (see comments). BMJ 1992; 305(6864):1256-59.

4. Gallagher BJ, Jones BJ, Eaton KE. A sex-specified effect of obstetric complications in symptoms of schizophrenia. Clin Schizophr and Relat Psychoses 2014; 8(3):143-8. 5. Geddes JR, Lawrie SM. Obstetric complications and schizophrenia: a meta-anaylsis. Br J Psychiatry 1995; 167:786-93.

6. Schwarzkopt SB, Nasrallah HA, Olson SC, CoffmanJA, Mclaughlin JA. Perinatal complications and genetic loading in schizophrenia: preliminary findings. Psychiatry Res 1989; 27(3):233-9.

7. Murray RM, Lewis SW, Reveley AM. Towards an etiological classification of schizophrenia. Lancet 1985; 1(8436):1023-26.

8. Nimgaonkar VL, Wessely S, Murray RM. Prevalence of familiality, obstetric complications, and structural brain damage in schizophrenic patients. Br J Psychiatry 1988; 153:191-7.

9. Reddy R, Mukherjee S, Schnur DB, Chin J, Degreef G. History of obstetric complications, family history, and CT scan findings in schizophrenic patients. Schizophr Res 1990; 3(5-6):311-4.

10. Verdoux H, Bourgeois M. A comparative study of obstetric history in schizophrenics, bipolar patients and normal subjects. Schizophr Res 1993; 9(1):67-9.

11. Andreasen NC, Arndt S, Alliger R, Miller D, Flaun M. Symptoms of schizophrenia: methods, meanings, and mechanisms. Arch of Gen Psychiatry 1995; 52:341-51.

12. Malaspina D, Friedman JH, Kaufmanns C, Brud- er G, Amador X, Strauss D et al. Psychobiological heterogeneity of familial and sporadic schizophrenia. Biol psychiatry 1998; 43(7):489-96.

13. Galderisi S, Merlotti E, Mucci A. Neurobiological background of negative symptoms. Eur Arch Psychiatry Clin Neurosci 2015; 265(7):543-58.

14. Malaspina D, Goezt R, Scott Y, Berman A, Harkavy-Fried-Man J, Printz D, et al. Relation of familial schizophrenia to negative symptoms but not to the deficit syndrome. Am J Psychiatry 2000; 157(6):994-1003.

15. Verdoux H, Geddes JR, Takei N, Lawne SM, Bovet P, Eagles JM. Obstetric complications and age at onset in schizophrenia: an International Collaborative Meta-analysis of individual patient data. Am J Psychiatry 1997;154:9.

16. Zahid MA, Ohaeri JU. Schizophrenia psychopathology in Kuwaiti Arab sample. Psychopathology 2010; 43:345-56.

17. Kaye DK, Kakaire O, Osinde MO. Systematic review of the magnitude and case fatality ratio for severe maternal morbidity in sub-Saharan Africa between 1995 and 2010. BMC Pregnancy and Childbirth 2011; 11:65.

18. Onu JU, Ohaeri JU. Familial aggregation of mood disorders among relatives of schizophrenia probands admitted in a hospital in South-Eastern Nigeria: A family comparative study. Niger Postgrad Med J 2018; 25:1-7.

19. Onu JU, Unaogu NN, Ohaeri JU, Onwukwe JU. Handedness in schizophrenia: Any familial difference? EC Neurology 2017; 5.6:216-22.

20. National Institute of Mental Health (NIMH) Genetics Initiative: Family Interview for Genetic Studies (FIGS). Rockville: National Institute of Mental Health, 1992.

21. Lewis SW, Owen MJ, Murray RM. Obstetric complications and schizophrenia: methodology and mechanisms. In Schizophrenia: Scientific progress (Schlz S.C and Tamminga C.A), Oxford: Oxford University Press 1989, 56-68.

22. Overall JE, Gorham DR. The Brief Psychiatric Rating Scale. Psychol Rep 1962; 10:799-812.

23. Zanello A, Berthoud L, Ventura J, Merlo MCG. The Brief Psychiatric Rating Scale; factorial structure and its sensitivity in the treatment of outpatients with unipolar depression. Psychiatry Res 2013; 210(2):626-633.

24. Andreasen NC. The Scale for the Assessment of Negative Symptoms. Iowa City: University of Iowa, 1983. 25. Peralta V, Cuesta MJ. Positive and Negative symp- 
toms/syndromes in schizophrenia: reliability and validity of different diagnostic systems. Psychol Med 1995; 25:4350.

26. Cardno AG, Sham PC, Murray RM, McGuffin P. Twin study of symptom dimensions in psychoses. $\mathrm{BrJ}$ Psychiatry 2001; 179:39-45.

27. DeRose P, Lencz T, Burdich KE, Siris SG, Kane JM, Malhotra AK. The genetics of symptom-based phenotypes: towards a molecular classification of schizophrenia. Schizophr Bull 2008; 34(6):1047-53.

28. Brzustowics LM, Honer WG, Chow EW, Hogan J, Hodgkinson K, Bassett AS. Use of a quantitative trait to map a locus associated with severity of positive symptoms in familial schizophrenia to chromosome 6p. Am J Hum Genet 1997; 61:1388-96.
29. Wilcox MA, Faraone SV, Su J, Van Eerdewegh P, Tsuang MT. Genome scan of three quantitative traits in schizophrenia pedigree. Biol Psycbiatry 2002; 52:847-54.

30. Smith GN, Kopala LC, Kinsella A, Waddington JL. Obstetric complications, the putative familial-sporadic distinction, and tardive dyskinesia in schizophrenia. $\mathrm{Br}$ J Psycbiatry 1990; 157:578-84.

31. Kirov G, Jones PB, Harvey I, Lewis SW, Toone BK, Rifkin L et al. Do obstetric complications cause the earlier age at onset in males than female schizophrenics? Schizophr Res 1996; 20(1-2):117-24.

32. Cannon M, Jones PB, Murray RM. Obstetric complications and schizophrenia: historical and meta-analytic review. Am J Psycbiatry 2002; 159:1080-92. 